\title{
Patient compliance with inhaled medication: Does combining beta-agonists with corticosteroids improve compliance?
}

\author{
C.M. Bosley*, D.T. Parry**, G.M. Cochrane***
}

Patient compliance with inhaled medication: Does combining beta-agonists with corticosteroids improve compliance? C.M. Bosley, D.T. Parry, G.M. Cochrane. CERS Journals Ltd 1994.

ABSTRACT: Patient compliance with an inhaled corticosteroid may be greater if it is combined with a beta-agonist. This study compared compliance with an inhaled corticosteroid (budesonide), and a short-acting inhaled beta-agonist (terbutaline sulphate), and a Turbuhaler inhaler containing a combination of the two drugs.

In an open, multicentre, parallel group study 102 asthmatic patients were randomly divided into two groups, either receiving the two drugs in separate Turbuhalers or combined into one Turbuhaler. A twice daily regimen was prescribed and a preweighed metered-dose inhaler (MDI) of salbutamol was provided for rescue use. Compliance was measured using the Turbuhaler Inhalation Computer (TIC), which recorded the time and date of each inhalation over a 12 week period. Forced expiratory volume in one second $\left(F E V_{1}\right)$ and forced vital capacity (FVC) measurements were carried out at week 0,6 and 12 .

Results from 72 patients were analysed. The average compliance was $60-70 \%$. Treatment was taken as prescribed on $30-40 \%$ of the study days, and over-usage occurred on less than $10 \%$ of days. Only $15 \%$ of patients took the drugs as prescribed for more than $80 \%$ of the days.

Compliance was no greater in patients using the combined inhalers. Other ways of improving patient self-management need further investigation.

Eur Respir J., 1994, 7, 504-509.
Depts of *Psychiatry and Thoracic Medicine, United Medical and Dental Schools, Guy's Hospital, London, UK.

Correspondence: G.M. Cochrane Dept of Thoracic Medicine

United Medical and Dental Schools

Guy's Hospital

London SEl 9RT

UK

Keywords: Asthma

treatment refusal

Received: April 191993

Accepted after revision October 91993
One of the components of the management of chronic disease is the presciption of long-term regular medication. Studies of patients on long-term treatment have shown that at least half take less than $80 \%$ of the prescribed medication, i.e. are "noncompliant" [1]. Longterm regular inhaled medication is often prescribed in the management of asthma, and noncompliance with these regimes is a significant problem among asthmatics [2], and has been shown to be related to morbidity [3]. The British Thoracic Association has also cited patient noncompliance as a significant factor in asthma deaths [4].

There is a widely held belief that many patients neglect to use inhaled steroids because they do not offer the immediate relief afforded by beta-agonists or because of fear of side-effects [5-7]. MAWHINNEY et al. [8] measured compliance with an inhaled anti-inflammatory and an inhaled corticosteroid within a clinical trial using the Nebulizer Chronologue. They found disappointingly low levels of compliance with a four times daily regimen. Compliance with a bronchodilator was measured in the study by RAND et al. [9], also using the Nebulizer Chronologue. On a three times daily regimen, compliance levels were slightly better than those reported by Mawhinney et al. [8]. Dompeling et al. [10] compared compliance with an inhaled corticosteroid and a bronchodilator using capsule count. They found that although compliance with the steroid was significantly less than with the bronchodilator, the two were highly correlated, and they suggest that compliance is patientdependent rather than drug-dependent. As is always the case with pill count methods, their compliance levels were probably overestimated and no record of pattern of use can be obtained.

The aim of this study was to measure concurrent compliance both with inhaled steroids and beta-agonists, and to compare the patterns of use for each drug within as normal a clinical setting as possible. Combining the two drugs into a single inhaler may be expected to improve overall compliance by simplifying the regimen [11] and by ensuring that the steroid was inhaled regularly along with the beta-agonist, therefore the effect of a combined preparation on compliance was also examined.

The Study Objectives were: 1) to obtain an accurate measurement of compliance with inhaled beta-agonist and steroids within usual clinical practice; 2) to identify drug-taking patterns, in particular comparing betaagonist with corticosteroid; and 3) to assess whether combining the two drugs into a single inhaler is associated with better compliance. 


\section{Patients and methods}

\section{Patients}

Patients were recruited from four general practices and a hospital out-patient clinic. All patients were asthmatics, aged 18-70 yrs, who required treatment with regular inhaled steroids and beta-agonists (as assessed by their own doctor) and were approached by letter.

\section{Study design}

This was an open multicentre parallel group study. Patients were randomly divided into two groups: the control group $(n=51)$ were given two Turbuhaler inhalers, one containing terbutaline $\left(250 \mu \mathrm{g} \cdot \mathrm{dose}^{-1}\right)$ and one containing budesonide $\left(100 \mu \mathrm{g} \cdot \mathrm{dose}^{-1}\right)$; the treatment group $(n=51)$ were given one Turbuhaler inhaler containing a fixed combination of the same drugs (equivalent dosages). Patient compliance with the Turbuhalers was measured over a 12 week period and compared.

\section{Methods}

In total, 102 patients were recruited (62 females). They were randomly divided into treatment and control groups as given above ( $n=51$ in each group) and asked to take $2(400 \mu \mathrm{g}$ budesonide and $500 \mu \mathrm{g}$ terbutaline) or 4 (800 $\mu \mathrm{g}$ budesonide and $1,000 \mu \mathrm{g}$ terbutaline) inhalations daily from each inhaler, according to the severity of their asthma as assessed by their own clinician. Fifty two patients were in the lower dose group of 2 inhalations daily (seven patients were later increased to 4 inhalations, and one decreased to 2 inhalations because of palpitations). Pre-weighed salbutamol aerosol inhalers were also provided, for rescue use only.

Patients were asked to attend the clinic at 6 and 12 weeks. It was intended that the study period should differ as little as possible from normal; therefore, peak flow monitoring and diary cards were not used (as this was not normal practice for the general practices in the management of long-standing asthmatics).

Simple respiratory function tests forced expiratory volume in one second $\left(\mathrm{FEV}_{1}\right)$ and forced vital capacity (FVC) were carried out at week 0, 6 and 12 using the micro-spirometer [12]. Replacement Turbuhalers were provided at week 6 .

By the end of the study, 72 patients were evaluable. Demographic and other details are given in table 1 . Nineteen patients were lost to follow-up during the study. The reasons for the withdrawal of a further 11 patients were: lack of efficacy (3); erroneous inclusion (1); adverse event (4); Turbuhaler damaged (1); Turbuhaler Inhalation Computer malfunction 1; and other (1). Patients who were withdrawn had a younger mean \pm SD age $(39 \pm 14 \mathrm{yrs})$ than those who remained $(45 \pm 15 \mathrm{yrs}$; $\mathrm{p}=0.03$ ) but did not differ in any other way.
Table 1. - Patient details $(n=72)$

\begin{tabular}{ll}
\hline Sex M/F & $28 / 44$ \\
Age* yrs & $44(20-69)$ \\
Duration of illness* yrs & $13.9(0.25-54)$ \\
Study Time* days & $89(41-133)$ \\
Treatment Group & \\
$\quad$ Separate inhalers n & 36 \\
Combined inhaler n & 36 \\
Dose Group (budesonide) & \\
$200 \mu \mathrm{g} n$ & 34 \\
$400 \mu \mathrm{g} n$ & 38 \\
*: data presented as mean and range in parenthesis. M: male; \\
F: female.
\end{tabular}

\section{Measurement of compliance}

Each Turbuhaler contained a Turbuhaler Inhalation Computer (TIC) concealed within its base. This device contains a microphone and a real-time recorder. When a patient uses the inhaler, they turn the grip clockwise, then anti-clockwise until a "click" is heard. The dose is then loaded and the patient inhales deeply from the Turbuhaler. The microphone identifies the "click" and the noise characteristics of the inhalation when a flow of 24-30 l. $\mathrm{min}^{-1}$ is achieved and maintained for $0.7 \mathrm{~s}$. Both the click and the airflow must occur for the inhalation to be recorded as valid. The date and time of the valid inhalation is recorded in a memory chip using a 16-bit format and power is obtained using a long operating time battery. Information from the device is directly downloaded to a programmed IBM computer. The only outward difference to the Turbuhaler is that it is slighter longer $(33 \mathrm{~mm})$ and heavier than usual [13].

Each Turbuhaler contains 200 doses measured mechanically by the number of times the grip is turned. An additional indirect measure of compliance was, therefore, obtained by counting the number of grip turns remaining.

The calculation of compliance levels was approached in two ways. Firstly, overall percentage compliance was calculated for the whole period as:

$$
\frac{\% \text { compliance }=\text { number of doses taken } \times 100}{\text { number of doses prescribed }}
$$

Secondly, day-by-day use of Turbuhalers was examined, so that the percentage of days when the correct number of doses was taken at the right time (morning and evening) was calculated. The day ended at 0200 to account for patients who regularly keep late hours. The percentage of days when the Turbuhalers were not used, or used too much, or when only half (or less) of the prescribed dose was taken was also calculated.

\section{TIC malfunction}

For the 72 patients who completed the study, 215 TlCs were returned. Of these, 12 malfunctioned recording 
dates at random, and were excluded from the analysis. (As each patient had at least two inhalers, one TIC is not the equivalent of one patient). Another 47 had recorded inhalations over an initial period and then apparently no more inhalations were made. It was unclear in these cases whether patients had ceased to use the inhalers or the battery had failed. A zero reading was displayed by $17 \mathrm{TICs}$, due either to total battery failure or total noncompliance. Unfortunately, by the time the TICs returned to base, where the last test dose was taken, many had expired batteries and so the exact time of battery failure remained unknown. Although $65 \%$ of the TICs give accurate compliance readings, these technical problems lead to some difficulty in interpreting the recorded data of $64(30 \%)$ of the TICs. Excluding all of them would exclude some patients with low levels of compliance and result in artificially high overall compliance, and including them at face value may well result in underestimation. Compliance levels have, therefore, been calculated by interpreting the data from the 64 suspect TICs using several alternative methods.

Methods of TIC data analysis. A) all TICs assessed at face value; B) for those TICs which showed a sudden stop in dose recording, the compliance level over the period prior to possible battery failure was calculated; C) as A but excluding TICs which gave zero reading; and D) as B but excluding TICs which gave zero reading.

Grip turn data. The grip turn data correlated well with the TIC data but when compared with the TICs known to be working accurately, grip turns consistently gave a higher level of compliance. This overestimation may be due to patients double-clicking the Turbuhaler before each dose, or dumping doses prior to clinic visits $[8,9,14]$.
Rescue beta-agonist use. The salbutamol aerosols were weighed at the start and end of the study to assess additional beta-agonist use.

\section{Patient consent}

In order to obtain as accurate a picture of "normal" behaviour as possible, patients were not told that the Turbuhalers contained TICs or that their compliance was being monitored. They were aware that each Turbuhaler could count the number of doses given, as the appearance of the red marker on Turbuhaler indicates that there are few doses left. Patients were given full information on the nature of the combined preparation. Approval was granted by the local Ethics Committee.

\section{Statistical analysis}

The compliance levels with each type of inhaler were not normally distributed and were compared using the Mann-Whitney test.

\section{Results}

Using the TIC data, the mean compliance for each drug across all patients was $60-70 \%$ for all of the drugs used, and although compliance was improved with the combined preparation this did not reach significance using the Mann-Whitney test (table 2). Figure 1 shows the distribution of the average compliance figures per patient for each type of drug, showing the majority of patients taking less than $80 \%$ of the prescribed dose. If, for those patients taking budesonide and terbutaline separately, a mean compliance is calculated per patient, it is found that $40-50 \%$ of patients took less than $80 \%$ of the dose

Table 2. - Compliance results

\begin{tabular}{|c|c|c|c|c|c|c|}
\hline \multirow[b]{2}{*}{ Drug } & \multirow[b]{2}{*}{$\begin{array}{l}\text { Method } \\
\text { of } \\
\text { analysis }\end{array}$} & \multicolumn{4}{|c|}{$\begin{array}{c}\text { Day-by-day use } \\
\% \text { of days }\end{array}$} & \multirow[t]{2}{*}{$\begin{array}{c}\% \text { compliance over } \\
\text { total period }\end{array}$} \\
\hline & & $\begin{array}{l}\text { Correct } \\
\text { dose }\end{array}$ & $\begin{array}{c}<50 \% \text { of } \\
\text { dose }^{+}\end{array}$ & $\begin{array}{l}\text { All doses } \\
\text { omitted }\end{array}$ & $\begin{array}{l}\text { Extra doses } \\
\text { taken }\end{array}$ & \\
\hline Budesonide & $\begin{array}{c}\text { A } \\
\text { B } \\
\text { C } \\
\text { D } \\
\text { Grip turns }\end{array}$ & $\begin{array}{c}30 \\
41 \\
36 \\
30 \\
-\end{array}$ & $\begin{array}{l}56 \\
52 \\
48 \\
42 \\
-\end{array}$ & $\begin{array}{l}38 \\
31 \\
26 \\
17 \\
-\end{array}$ & $\begin{array}{l}5 \\
6 \\
6 \\
7 \\
-\end{array}$ & $\begin{array}{l}60 \pm 37 \\
67 \pm 35 \\
68 \pm 36 \\
76 \pm 34 \\
88 \pm 31\end{array}$ \\
\hline Terbutaline & $\begin{array}{c}\text { A } \\
\text { B } \\
\text { C } \\
\text { D } \\
\text { Grip turns }\end{array}$ & $\begin{array}{r}30 \\
36 \\
41 \\
-\end{array}$ & $\begin{array}{r}54 \\
33 \\
47 \\
49 \\
-\end{array}$ & $\begin{array}{r}34 \\
49 \\
25 \\
17 \\
-\end{array}$ & $\begin{array}{r}6 \\
27 \\
7 \\
8 \\
-\end{array}$ & $\begin{array}{c}63 \pm 3 \\
770 \pm 37 \\
72 \pm 37 \\
76 \pm 35 \\
88 \pm 32\end{array}$ \\
\hline Combined & $\begin{array}{c}\text { A } \\
\text { B } \\
\text { C } \\
\text { D } \\
\text { Grip turns }\end{array}$ & $\begin{array}{c}38 \\
42 \\
42 \\
45 \\
-\end{array}$ & $\begin{array}{c}46 \\
43 \\
42 \\
39 \\
-\end{array}$ & $\begin{array}{l}30 \\
24 \\
24 \\
18 \\
-\end{array}$ & $\begin{array}{l}5 \\
6 \\
6 \\
7 \\
-\end{array}$ & $\begin{array}{l}67 \pm 30 \\
76 \pm 28 \\
69 \pm 28 \\
86 \pm 27 \\
93 \pm 33\end{array}$ \\
\hline
\end{tabular}

*: mean \pm SD. ${ }^{+}$: includes days when doses omitted. Methods of TIC data analysis: A) all TICs assessed at face value; B) for those TICs which showed a sudden stop in dose recording, the compliance level over the period prior to possible battery failure was calculated; C) as A but excluding TICs which gave zero reading; D) as B but excluding TICs which gave zero reading. TIC: Turbuhaler Inhalation Computer; Grip: grip turn data. 


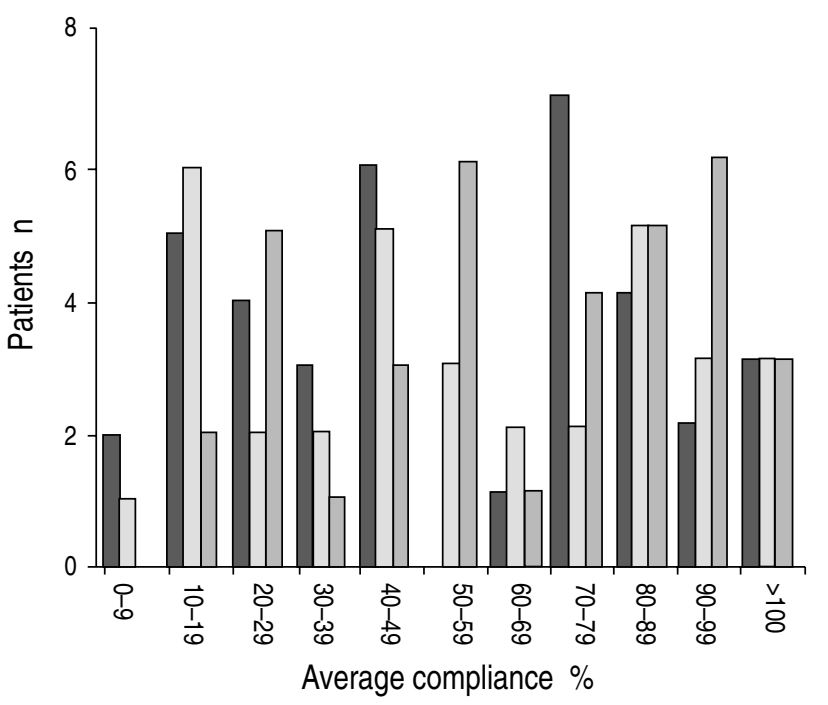

Fig. 1. - The average $\%$ compliance with each type of inhaler was calculated for each patient. The figure shows the distribution of these compliance levels for each type of inhaler. $\square$ : budesonide $n=36$; $\square$ : terbutaline $n=34 ; \square$ : combined $n=36$.

prescibed. $\mathrm{N}$ values are 36 for the budesonide and combined groups and 34 for the terbutaline group.

Table 2 also shows the percentage of days that the correct dose was taken, and the percentage of under-use and over-use days across all patients. The day-by-day analysis reveals that on $30-45 \%$ of the days the correct dose was taken at the right time (morning and evening). Between 17-38\% of days medication was omitted altogether, and less than $50 \%$ of the dose was taken on about half of the days. Drugs were over-used on less than $10 \%$ of days. Analysis of individual patients showed that only $14 \%$ of patients took the medication as prescribed (the correct dose twice daily) for more than $80 \%$ of the days (fig. 2). There is no significant difference between any of the drugs, and the beta-agonist was not more likely to be over-used than the other drugs. There was little use made of the "rescue" salbutamol MDI (total mean (SD) use for the group on separate inhalers $=66(132) \mu \mathrm{g}$; total mean (SD) use for the group on combined inhalers $=114(156) \mu \mathrm{g})$; and there was no significant difference between the groups. There was no difference in compliance between patients prescribed two inhalations twice daily and those prescribed one inhalation twice daily.

Table 3. - Respiratory function tests

\begin{tabular}{|c|c|c|c|c|c|c|}
\hline \multirow[b]{2}{*}{ Visit } & \multicolumn{3}{|c|}{ Seperate } & \multicolumn{3}{|c|}{ Combined } \\
\hline & $\mathrm{n}$ & $\begin{array}{l}\mathrm{FEV}_{1} \\
\% \text { pred }\end{array}$ & $\begin{array}{c}\text { FVC } \\
\% \text { pred }\end{array}$ & $\mathrm{n}$ & $\begin{array}{c}\mathrm{FEV}_{1} \\
\% \text { pred }\end{array}$ & $\begin{array}{l}\text { FVC } \\
\% \text { pred }\end{array}$ \\
\hline 1 & 34 & $71 \pm 22$ & $73 \pm 22$ & 34 & $76 \pm 36$ & $80 \pm 21$ \\
\hline 2 & 33 & $79 \pm 23$ & $77 \pm 20$ & 32 & $78 \pm 27$ & $80 \pm 21$ \\
\hline 3 & 34 & $77 \pm 24$ & $75 \pm 24$ & 31 & $76 \pm 22$ & $90 \pm 22$ \\
\hline
\end{tabular}

Data are presented as mean \pm SD. $\mathrm{FEV}_{1}$ : forced expiratory volume in one second; FVC: forced vital capacity.

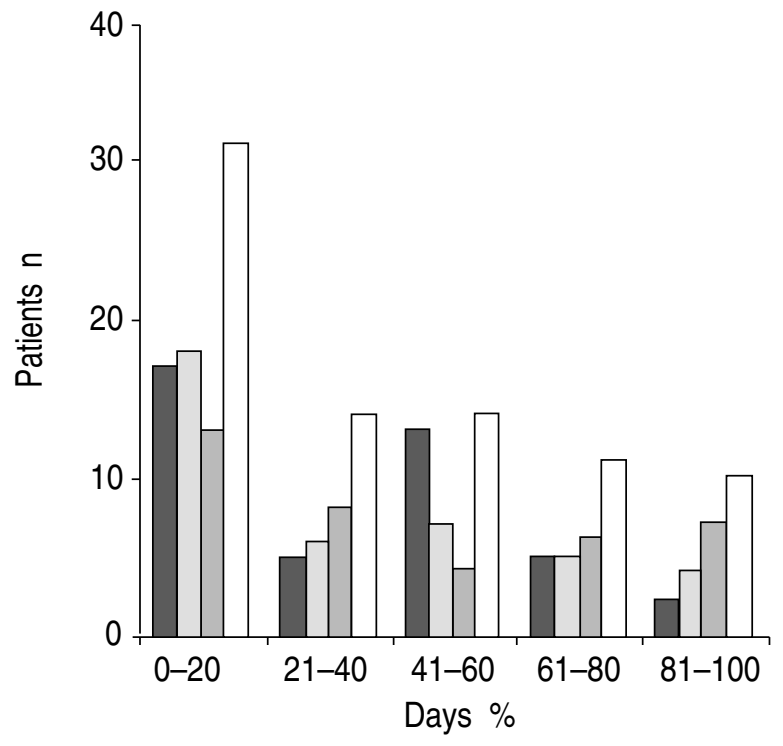

Fig. 2. - The percentage of days when each patient took their inhalers as prescribed (one or two puffs twice daily) was calculated for each type of inhaler. $\square$ : budesonide; $\square$ : terbutaline; $\square$ : combined; $\square$ : whole sample; average for each patient for all drugs.

The TIC data revealed each patient's individual pattern of drug use, each of which probably have different clinical effects. Some patients stop and start their use of inhalers; this may be an appropriate response to symptom pattern but without symptom records no firm conclusion may be reached. Others show low and erratic use, potentially more worrying as it may reflect an inadequate response to symptoms and persistent undertreatment. Clinic visits were not preceded by multiple activations of the inhalers. In a few instances they were followed by an increase in inhaler use. This effect was not great and was not sustained.

Respiratory function tests were similar in both drug groups and did not change throughout the study (table 3).

\section{Withdrawals}

As indicated above, there were 30 patients not included in the final compliance analysis. The largest group consisted of those patients who were lost to follow-up despite active efforts to draw them back into the study. This reflects normal clinical experience and is another form of noncompliance.

\section{Discussion}

The compliance levels found are similar to those reported for other chronic diseases [1], with only 50-60\% of patients taking $>80 \%$ of the prescribed treatment over the whole treatment period. This confirms that patients with asthma are not any more likely to follow prescriptions, despite the distressing nature of their symptoms. It should be borne in mind that the patients 
studied are those who agreed to take part in a study, and that the most non-compliant patients are unlikely to be included in such a study (or tend to drop out). Therefore, the compliance figures may be an overestimate of the true level in the whole population.

When the day-by-day use is examined (by each method of analysis) it is revealed that only $14 \%$ of patients are compliant (that is, take the correct dose morning and evening, for more than $80 \%$ of the days) and there was no significant difference between the compliance with the corticosteroid and the bronchodilator. The daily compliance levels are very similar to the findings of RAND et al. [9], whose patients were asked to take a bronchodilator, ipatropium bromide, three times daily. They found that $15 \%$ of patients used their inhaler on average 2.5 or more times per day. In the study by MAwHINNEY et al. [8], only 1 patient out of $34(3 \%)$ took the medication (an anti-inflammatory) as prescribed for more than $75 \%$ of the days, with patients taking the drugs as prescribed on a mean of $37 \%$ of the days. In the study by MANN et al. [15], which measured compliance with an inhaled corticosteroid using the Nebulizer Chronologue, underuse (taking less than the number of doses prescribed) was found on $69 \%$ of the days. The four times daily regimen used in the studies by MAWHINNEY et al. [8] and MANN et al. [15] may account for the lower levels of compliance in these studies. CRAMER et al. [16] found that compliance decreased from $81 \%$ on a twice daily regimen to $39 \%$ on a four times daily regimen. Patients had some awareness of compliance monitoring both in the study by MAWHINNEY et al. [8] and RAND et al. [9] and this may well have affected behaviour. In both, some patients were noted to have made multiple activations of the inhalers prior to follow-up visits. Awareness of monitoring was also shown to affect behaviour in the study by YeUNG et al. [17] using a mechanical counter on MDIs containing a beta-agonist and a steroid.

Since the present study was designed the safety of regular short-acting beta-agonists has been questioned [18], and their regular prescription is no longer recommended as part of the standard treatment for asthma [19]. However, it is still common for them to be used regularly in the morning and evening, the former because of morning wheeze and the latter to try to reduce nocturnal waking.

Combining the drugs was expected to be associated with higher compliance for two reasons: by reducing the number of inhalers used and thereby simplifying the regimen, and by allowing the steroid to be taken along with the beta-agonist, thought to be the preferred drug. The TIC data with the detailed day-by-day information have revealed evidence that the patterns of beta-agonist and steroid use are very similar. If patients do prefer short-acting beta-agonists over steroids (and there is little evidence that this is the case) then this preference was not reflected in the drug-taking behaviour. Betaagonist was also available from the salbutamol MDI rescue inhaler, but these were little used by the patients and do not seem to substantially alter the beta-agonist pattern of use.
Whatever drives a patient into choosing whether or not to use their inhalers, the specific nature of the drug is less important than expected. These findings support the view of Dompeling et al. [10] that compliance is a patientdependent and not a drug-dependent issue. MANN et al. [15] also found that compliance with the corticosteroid did not change with asthma severity, so compliance is not a symptom driven behaviour. In view of low overall compliance levels, and the possible consequences in morbidity and mortality, it is important that the factors which affect patient compliance are identified and explored. Different forms of compliance can be identified using technology now available. Research aiming to identify the factors important in compliance and its improvement may be more effective if these different forms of behaviour are examined separately, rather than lumping a heterogeneous group together under the blanket heading of "noncompliance". Meluins et al. [20] point out that the concept of compliance should include issues such as open communication between doctor and patient, shared responsibility, mutual agreement, and patient self-regulation. Noncompliance may be a reflection of problems in any of these areas, resulting in patients' inability to respond to their own health needs and circumstances. This area requires further research to examine the causes of these problems and to evaluate possible interventions. The effective management of asthma depends upon finding ways to enable patients to fully participate in their own treatment.

Acknowledgements: The authors would like to thank Astra Clinical Research Unit for funding the study and for provision of the TICs and the doctors and nurses of Bermondsey and Lansdowne Medical Mission, Bermondsey Health Centre, Lakeside Health Centre and Gallion's Reach Health Centre, for their help with patient management and data collection.

\section{References}

1. Sackett DL, Snow JC. The magnitude of compliance and noncompliance. In: (Haynes RB, Taylor DW, Sackett DL, eds. Compliance in Health Care. Baltimore, John Hopkins University Press, 1979.

2 Anon. Are you taking the medicine? Lancet 1990; 335: 262-263.

3. Horn CR, Clark TJH, Cochrane GM. Compliance with inhaled therapy and morbidity from asthma. Respir Med 1990; 84: 67-70.

4. British Thoracic Association. Death from asthma in two regions of England. Br Med J 1982; 285: 12511255.

5. Barnes PJ, Fan Chung K. Difficult asthma. $\mathrm{Br}$ Med J 1989; 299: 695-698.

6. Worth H. Patient education in adult asthmatics. Lung 1990: i (Suppl.): 463-468.

7 Brewis RAL. Patient education, self-management plans and peak flow measurement. Respir Med 1991; 85: 457-462.

8. Mawhinney H, Spector AL, Kinsman RA, et al. Compliance in clinical trials of two nonbronchodilator, antiasthma medications. Ann Allergy 1991; 66: 294-299.

9. Rand CS, Wise RA, Nides M, et al. Metered-dose inhaler adherence in a clincial trial. Am Rev Respir Dis 1992: 146; 1559-1564. 
10. Dompeling E, Van Grunsven PM, Van Schayck CP, Folgering H, Molema J, Van Weel C. Treatment with inhaled steroids in asthma and chronic bronchitis: longterm compliance and inhaler technique. Fam Pract 1992; 9(2): 161-166.

11. Blackwell B. The drug regimen and treatment compliance. In: (Haynes RB, Taylor DW, Sackett DL, eds. Compliance in Health Care. Baltimore, Johns Hopkins University Press, 1979.

12. Chowienczik PJ, Lawson CP, James PNE, Cochrane GM. Evaluation of a new pocket-sized device for measurement of $\mathrm{FEV}_{1}$ and FVC. Thorax 1982; 37: 785.

13. Fagerstrom P-O, Marnfeldt G, Lindgren S. TIC, an instrument for compliance measurement of patients using inhaler. Proc AAMI 27th Annual Meeting 1992; (Abstract).

14. Spector SL, Kinsman RA, Mawhinney H, et al. Compliance of patients with asthma with an experimental aerosolized medication: implications for controlled clinical trials. $J$ Allergy Clin Immunol 1986; 77: 65-70.

15. Mann MC, Eliasson O, Patel K, Zuwallack RL. An evaluation of severity-modulated compliance with q.i.d. dosing of inhaled beclomethasone. Chest 1992; 102: 1342-1346.

16. Cramer JA, Mattson RH, Prevey ML, Scheyer RD, Ouellette VL. How often is medication taken as prescribed? J Am Med Assoc 1989; 261: 3272-3277.

17. Yeung M. O'Connor SA, Parry DT, Cochrane GM. Compliance with prescribed drug therapy and the management of asthma. Respir Med 1994; (in press).

18. Sears MR, Taylor DR, Print CG, et al. Regular inhaled beta-agonist treatment in bronchial asthma. Lancet 1990; 336: 1391-1396.

19. Van Schayck CP, Dompeling E, Van Herwaarden CLA, et al. Bronchodilator treatment in moderate asthma or chronic bronchitis: continuous vs on demand. A randomised controlled study. Br Med J 1991; 303: 14261431.

20. Mellins RB, Evans D, Zimmerman B, Clark NM. Patient compliance: are we wasting our time and don't know it? Am Rev Respir Dis 1992; 146: 1376-1377. 